\title{
Erratum to: Limited-area atmospheric energetics: illustration on a simulation of the CRCM5 over eastern North America for December 2004
}

\author{
Marilys Clément $^{1} \cdot$ Oumarou Nikiéma ${ }^{1} \cdot$ René Laprise $^{1}$
}

Published online: 20 March 2017

(C) Springer-Verlag Berlin Heidelberg 2017

\section{Erratum to: Clim Dyn \\ DOI 10.1007/s00382-016-3198-0}

In the original publication of the article, the author would like to correct the error in the figure caption 10. The correct figure caption should be "Fig. 10 Maps of time-averaged vertically integrated energy conversions of a time-mean into time variability available enthalpy $\mathrm{CA}$, and $\mathbf{b}$ timemean available enthalpy into time mean kinetic energy CTM".

The online version of the original article can be found under doi:10.1007/s00382-016-3198-0.

Marilys Clément

marilys.clement@gmail.com

1 Département des sciences de la Terre et de l'atmosphère,

Centre ESCER (Étude et Simulation du Climat à l'Échelle

Régionale), UQÀM, Stn. Downtown, P.O. Box 8888,

Montréal, QC H3C 3P8, Canada 
Fig. 10 Maps of time-averaged vertically integrated energy conversions of a time-mean into time variability available enthalpy $\mathrm{C}_{\mathrm{A}}$, and $\mathbf{b}$ time-mean available enthalpy into time mean kinetic energy $\mathrm{C}_{\mathrm{TM}}$ (a)

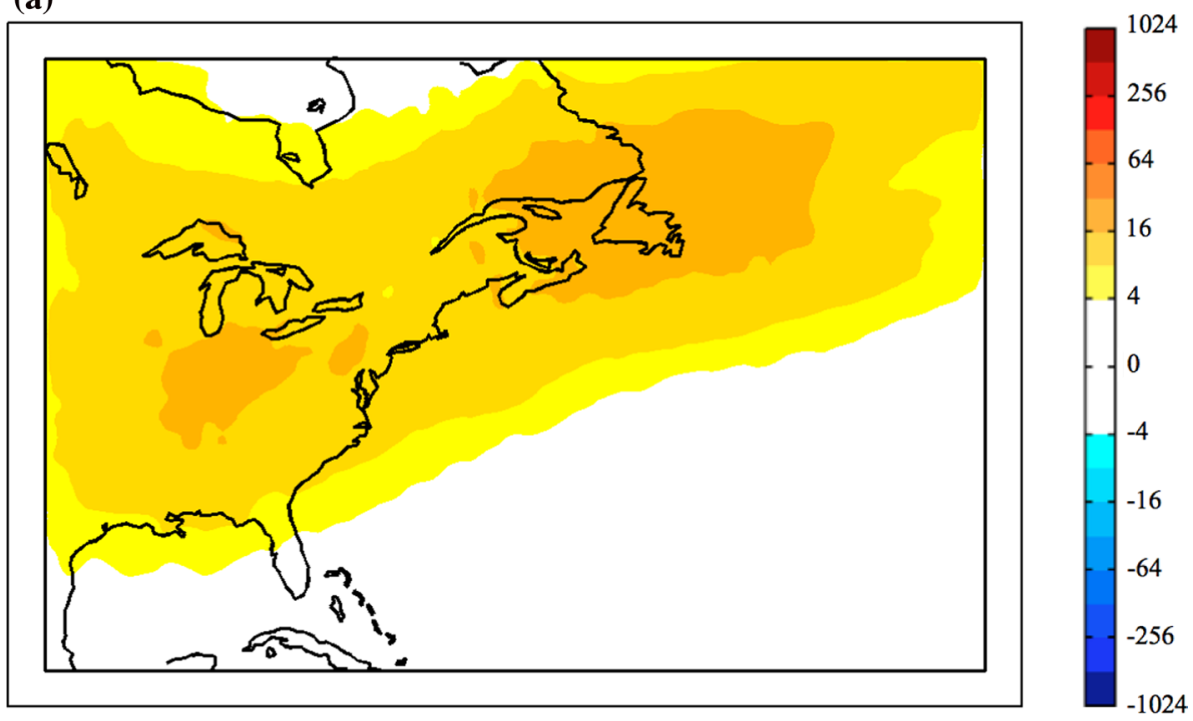

(b)

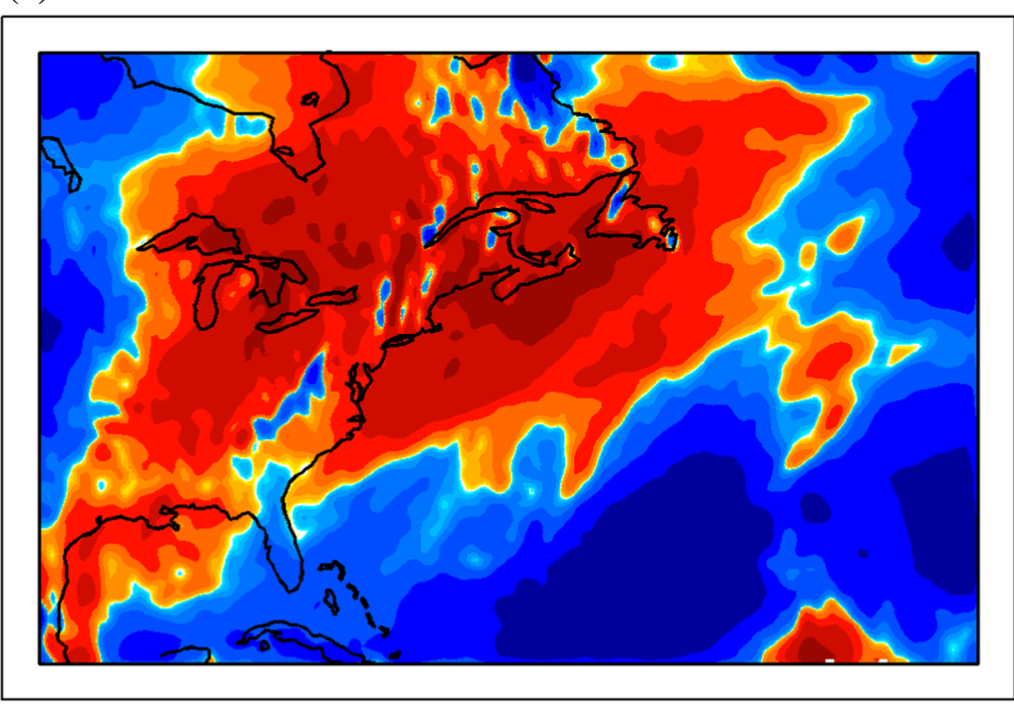

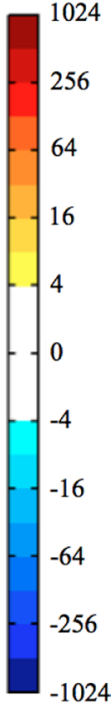

